\title{
The Necessity of Personal Freedom to Increase HCI Design Quality
}

\author{
Rüdiger Heimgärtner ${ }^{1}$, Helmut Windl ${ }^{2}$, and Alkesh Solanki ${ }^{2}$ \\ ${ }^{1}$ Intercultural User Interface Consulting (IUIC) \\ Lindenstraße 9, 93152 Undorf, Germany \\ ruediger.heimgaertneraiuic.de \\ ${ }^{2}$ Continental Automotive GmbH, Siemensstraße 12, \\ 93055 Regensburg, Germany \\ \{Helmut.Windl, Alkesh.Solanki\}@continental-corporation.com
}

\begin{abstract}
Creativity needs freedom. This must be considered by project managers and senior managers of HCI design organization. The improvement of quality through job enrichment and at the same time saving costs demands personal skills, expertise, motivation and creativity. Creating task models leads to a qualitative high-grade HCI design. Usage-centered design is based upon a user interface derived from a series of models containing interrelated task cases. Nevertheless, creative processes must have been installed. As creativity needs freedom to increase quality and efficiency in general, this should be widely applied. Job-enrichment achieved through expertise, motivation, creativity as well as thorough better planning is an essential step for creating qualitative $\mathrm{HCI}$ design.
\end{abstract}

Keywords: HCI design, freedom, creativity, quality.

\section{Superior HCI Design Requires Creativity}

Human Computer Interaction (HCI) - design like any other design activity requires predominantly systematic work. However, there is always a gap in the overall HCI design process, which requires a great deal of creativity in its conceptualization phase and it is almost impossible to bridge this gap with methods or structured approaches [1]. Even if the concept phase needs to be kept as small as possible for the sake of efficiency, HCI design contains process parts that are inherently "creative". Various approaches and methods try to systematize the design process through organized gathering of information about the use of the system to be designed and structuring the findings to deliver a sound base for the design of the user interface. Presenting the information about usage of a system in form of models provides a very fundamental basis for the creative step towards the design specification.

Usage-centered design is such a model-driven approach for presentation design and interaction design of software [2] and Web-based applications [3]. In contrast to user centered design, usage-centered design is based on formal, structured models that build together a seamless process from analysis phase to the final system. This robust and adaptable process has a proven record of application on a wide range of projects 
from small agile projects [4] to large-scale industrial tools development [5]. For projects coping with complex problems where efficiency, user performance, and safety are crucial it has led to radical improvements and innovations in user task and problem-solving performance [5].

The idea of usage-centered design is to derive a user interface directly from a series of models, and to delay the creative design as far as possible to collect, systematize and structure knowledge about the users, tasks, usage and environment of the system before the abstract models are resolved into a specific user interface presentation. The core of the approach is a detailed task model containing interrelated task cases (use cases in their essential form), which are derived from the roles users play against the system. Based on the task model the canonical prototype, which is an abstract model of the user interface is deduced, which is in the final creative step the groundwork for the detailed user interface [1]. Although the canonical prototype helps to reduce the gap between the abstract model and the real user interface, creativity is still the critical ingredient for an excellent user interface design. This creativity necessary for designing innovative and novel solutions requires training and education, talent and capability plus an environment supporting brainwork and solution finding. This environment is the investment a company has to spend in order to be successful in the marketplace and to acquire a sustainable competitive position by patenting the resulting innovations.

Simplistic or automated attempts to generate a user interface without creative processes have resulted, up to now, in user interfaces to be proved that superior usability can be the result of such an approach.

The innovations in HCI-Design can be roughly divided into the following fields: visual design and aesthetics, interaction, functionality and user interface architecture [1].

The user interface of the mobile phone "Apple iPhone" exhibits a well-known example of an innovative user interface architecture, which not only offers improved functionality, but also radically changes the way one interacts with the device. The key to such innovative user interfaces is creativity [6] of the designer paired with the necessary - but not necessarily project relevant - background knowledge. At the same time the user interface of number one mobile producer Nokia's Symbian OS is not able to deliver the ultimate user experience what Google's Android and Apple's iOS4 are able to and for that reason Nokia has been losing its substantial amount of market share.

\section{Creativity Needs Personal Freedom}

According to Von Stamm [7], "Creativity is not something where someone who has never worked in that field before suddenly gets this marvelous idea. Creativity is relating a concept to a particular body of knowledge. The existing body of knowledge is as important as the novel idea and creative people spend years and years acquiring and refining their knowledge base - be it music, mathematics, arts, sculpture or design." [7]. In this sense, creativity is the process of deriving new ideas from a huge and refined knowledge base. Creativity can be regarded as "the application of knowledge and skills in a new way to achieve a valued goal." [8]. 
According to Amabile [9], within every individual, creativity emerges as a function of three parameters: expertise, creative-thinking skills, and motivation. Managers can influence these components positively by specifying workplace practices and conditions.

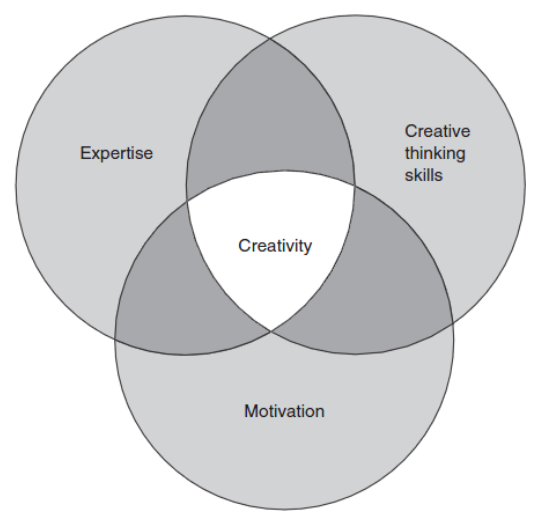

Fig. 1. The components of creativity according to Amabile [9]

Amabile [9] identified six general categories of managerial practice that affect creativity. These are

- challenge (of matching people with the right assignment),

- freedom (of autonomous working which boosts intrinsic motivation and sense of ownership),

- resources (time, money and physical space),

- work-group features (designing mutually supportive teams/groups with a diversity of perspectives and backgrounds),

- supervisory encouragement (praising creative efforts - successful or unsuccessful; encouraging collaboration and communication within the team; creating environment with no worry of failure; creating a culture of "work and play(experiment/explore)" promoting enjoyment), and

- organizational support (mandating information sharing, open communication and collaboration and ensuring that political problems do not foster).

Amabile [10] also looked at whether our feelings affect our creativity. During her research on projects which required creativity and innovation such as new product developments, new processes and solving complex client problems (she characterized all these tasks as 'knowledge work') she found that there exists a purely linear relationship: the greater the positive affect (the happier the person) the greater their creativity (this reflects the requirement that successful and fruitful thinking needs 
freedom e.g. based on Aristotle: the thinker needs to be freed from physical work). Other studies from Amabile [10] show that there are positive effects if the person has enough room to do what he or she wants to do.

\section{3 "Personal Freedom"}

Both for additional creativity and also for building up required background knowledge, personal freedom outside the everyday project work is absolutely necessary. This available scope / personal space can be used for activities which allow the employee to have more fun during his or her work and help the employee to acquire creative-thinking skills or to improve it. Of course, these activities should also have clearly specified strategic goals that are aligned with organisational goals. In this way, creativity and innovation are supported [11]. The effects of job enrichment on employees are satisfaction, motivation, involvement, and performance, because relieving the employee allows him or her to create more personal freedom through higher performance/productivity [12]; or to use that available scope more effectively than before measured by job diagnostic surveys [13, 14]. This promotes, alongside high internal motivation, high satisfaction and high-quality work performance, the formation of new abilities and skills for the employee, which automatically increases his or her efficiency. This is particularly the case for HCI design based on creativity. Better design and functionality, fitting better the user's needs and tasks, can be achieved through better knowledge about customers and technologies eventually leading to higher quality of HCI design and better usability. Lack of innovation, due to a lack of personal freedom to acquire new knowledge and skills, leads to substantial competitive disadvantages, which is even more true in the context of HCI design. Especially this is the case when the HCI design is gaining more and more importance as a salient feature of product differentiation.

\section{Basic Problem: No Freedom Available}

As result of overly tight planning which is not foresighted enough, unplanned efforts in development cause resource shortages. Even though under some circumstances, time pressure can enhance creativity, managers do contribute in killing the creativity by planning under the "threshold of sufficiency" or by setting fictitious or unrealistic deadlines to simulate the time pressure eventually. Under such tight circumstances in order to avoid endangering of the project, predominantly the measures to maintain the project on track are carried out and all the work-time is invested in keeping up with the extremely tight time schedules. In this way, the creativity and therefore any scope for innovation is destroyed. In fact the creativity is channelized in other direction e.g. how to get additional resources. Creativity often takes time to explore new concepts, to put together unique solutions, and to wander through the maze of the unknown / unpredictable. In order to achieve innovation, planning personal freedom is necessary 
as it is anyway impossible to plan $100 \%$ resource utilization during the development of the HCI design, as outstanding problems of the concept phase need to be handled and thus unplanned expenditure of time and money occurs.

\section{Possibilities for Creating Personal Freedom and Associated Problems}

There are various possibilities for creating personal freedom. Building personal freedom through increasing productivity could be accomplished, for example, through the application of methods like job enrichment and/or job engineering [14]. In particular, job enrichment leads to more independence through empowerment and autonomy and in this way to more possibility of choices and freedom, but also to taking more responsibility [15] as well as to higher job performance [16]. Barrick \& Mount [16] found that autonomy does play a moderating role on the relationships between personality dimensions (cf. Big Five ${ }^{1}$ ) and job performance. The emergence of personal freedom within the normal working day is supported above all by healthy workers' high levels of intrinsic motivation [15]. According to [17], work performance is a function of the product of opportunity, capacity, and willingness. For this, securing the health and well-being of the employees is indispensable. This is made possible primarily through a congenial working-atmosphere which supports team work and an acceptable workload through suitable resource planning (resulting in the establishment of a culture of trust [18]). Additionally, resource shortages can be avoided or lessened and personal freedom created via reserving capital to plan extra time. E.g. full time employees are supplied with a basic resource buffer of approximately $20 \%$ up to $50 \%$. A proportional creation of personal freedom to support creativity and innovation has already been tried out by many companies and today these companies are the innovation forerunners. Two examples are $3 \mathrm{M}$ and Google (cf. HR Policies of 3M [19] \& Google [20]). One of the pillars of the "3M Way" was that employees could seek out funding from a number of company sources to get their pet projects off the ground. Official company policy allowed employees to use $15 \%$ of their time to pursue independent projects. The company explicitly encouraged risks and tolerated failure. 3M's creative culture foreshadowed the one that is currently celebrated unanimously at Google. Only few companies are as creative as Google. The marvel of Google is its ability to inculcate a sense of creative fearlessness and in the end, the resources and liberty Google entrusts to its employees infuse them with a rare sense of possibilities and obligation. Google's integrated culture comprises four key elements: mission, innovation, fun and reward. At Google there is a $20 \%$ rule whereby $20 \%$ of employees' time is spent on whatever project they desire [21]. However, the creation of personal freedom always requires some form of investment which initially causes outlays.

1 The "BigFive" consist of (a) Extraversion (e.g., sociable, talkative, and assertive), (b) Agreeableness (e.g., good-natured, cooperative, and trusting), (c) Conscientiousness (e.g., responsible, dependable, persistent, and achievement oriented), (d) Emotional Stability (viewed from the negative pole; tense, insecure, and nervous), and (e) Openness to Experience (e.g., imaginative, artistically sensitive, and intellectual). 


\section{Solving the Problem of Costs: Prioritizing Measures to Create Personal Freedom}

In order to increase its desirability and lower the costs of creating personal freedom, the identified measures need not be introduced all at once, but rather step by step:

Step 1: Planning time for the inventive tasks that need to be carried out within the scope of the project.

Step 2: Creation of additional personal freedom alongside the current project work for innovation which is not connected to the project at hand but can be introduced into future products.

Step 3: Promotion of training and further education e.g. project planning courses for project managers and executives or HCI training for designers and software developers (expertise and knowledge-oriented sustainable personnel management [22]).

Step 4: Job enrichment leads to the implicit creation of personal freedom through autonomy, as the degree of employees' self-effectivity (the satisfaction and feeling of having achieved something and being appreciated) is very high (this means that selfesteem (self-assessment is improved) and finally self-actualization increases [23]).

Step by step execution of the measures saves cost, also because the need for the lower-priority measures is lower when the higher-priority measures have already been introduced. In other words planning time for the inventive tasks in the project supports the building of experience and skills thus of innovation. These lead to a reduction in the measures required for training and further education or job enrichment.

\section{Conclusion}

Investment in an initial time buffer for creative tasks in HCI design is not only repaid via its effects in the form of higher productivity and product quality with financial gain but also in other ways like exponentially increased loyalty, motivation, or innovation emerging due to the development of synergy effects (e.g. via the feeling of belonging to an organization which is successful for this reason). In this way personal freedom is also created by the employees themselves resulting in creative and innovative HCI design.

\section{References}

1. Constantine, L.L., Windl, H., Noble, J., Lockwood, L.A.D.: From Abstraction to Realization: Abstract Prototypes Based on Canonical Components. Working Paper, The Convergence Colloquy (July 2003), http: / / www. foruse.com/articles/canonical . pdf

2. Constantine, L.L., Lockwood, L.A.D.: Software for use: A practical guide to the models and methods of usage-centered design. ACM Press, Addison-Wesley Publishing Co., New York (1999) 
3. Constantine, L.L., Lockwood, L.A.D.: Usage-Centered Engineering for Web Applications. IEEE Software 19(2) (March/April 2002)

4. Patton, J.: Extreme Design: Usage-Centered Design in XP and Agile Development. In: Constantine, L.L. (ed.) Proceedings of the First International Conference on UsageCentered, Task-Centered, and Performance-Centered Design forUSE 2002, Ampersand Press, Rowley (2002)

5. Windl, H.: Designing a Winner: Creating STEP 7 Lite with Usage-Centered Design. In: Constantine, L.L. (ed.) Proceedings of the First International Conference on UsageCentered, Task-Centered, and Performance-Centered Design for USE 2002. Ampersand Press, Rowley (2002)

6. Schumpeter, J.A.: The Theory of Economic Development: An Inquiry into Profits, Capital, Credit, Interest, and the Business Cycle. Transaction Publishers, N.J (1934)

7. Von Stamm, B.: Innovation, Creativity and Design. John Wiley and Sons, Chichester (2003)

8. Seltzer, K., Bentley, T.: The Creative Age: Knowledge and Skills for the New Economy Buckingham: Demos (1999), http: / /www. creativenet.org.uk

9. Amabile, T.: How to Kill Creativity. Harvard Business Review, 77-87 ( SeptemberOctober 1998)

10. Amabile, T.M., Barsade, S.G., Mueller, J.S., Staw, B.M.: Affect and Creativity Work. Administrative Science Quarterly 50, 367-403 (2005)

11. Orpen, C.: Effects of Job-Enrichment on Employee Satisfaction, Motivation, Involvement, and Performance - Field Experiment Human Relations, vol. 32(3), pp. 189-217 (1979)

12. Hackman, J.R., Oldham, G.R.: Motivation through the design of work: Test of a theory. Organizational Behavior \& Human Performance 15, 250-279 (1977)

13. Hackman, J.R., Oldham, G.R.: Development of the Job Diagnostic Survey. Journal of Applied Psychology 60, 159-170 (1975)

14. Umstot, D., Bell, C.H., Mitchell, T.R.: Effects of job enrichment and task goals on satisfaction and productivity: Implications for job design. Journal of Applied Psychology 61, 379 (1976)

15. Herzberg, F.: The Motivation to Work. John Wiley and Sons, New York (1959)

16. Barrick, M.R., Mount, M.K.: Autonomy as a moderator of the relationships between the Big Five personality dimensions and job performance. Journal of Applied Psychology 78, 111-118 (1993)

17. Blumberg, M., Pringle, C.: The Missing Opportunity in Organizational Research: Some Implications for a Theory of Work Performance. The Academy of Management Review 7(4), 560-569 (1982)

18. Miles, R.E., Snow, C.C.: The new network firm: A spherical structure built on a human investment philosophy. Organizational Dynamics 23(4), 5-19 (1995)

19. $3 \mathrm{M}$ HR Principles, $3 \mathrm{M}$,

http://solutions.3m.com/wps/portal/3M/en_Us/us-diversity/ diversity/3M/3m-invests-diversity/hr-principles/

20. Google Inc. Ten reasons to work for Google (2005), http: / /google.com/jobs/reasons.html

21. Byte, X.: Google's answer to investors is 702010 but is not enough, Yeald, http://yeald.com/Yeald/a/35701/ google_s_answer_to_investors_is_70_20_10_but_is_not_

22. Pfeffer, J.: Producing sustainable competitive advantage through the effective management of people. Academy of Management Executive, vol. 19, no. 4 (2005)

23. Maslow, A.: A theory of human motivation. Psychological Review 50, 370-396 (1943) 